\title{
SARS-CoV-2 mediated lung inflammatory responses in host: targeting the cytokine storm for therapeutic interventions
}

\author{
Purva Asrani $^{1} \cdot$ Md. Imtaiyaz Hassan ${ }^{2}$ (D)
}

Received: 9 August 2020 / Accepted: 7 October 2020 / Published online: 16 October 2020

(C) Springer Science+Business Media, LLC, part of Springer Nature 2020

\begin{abstract}
The recent exposure of novel coronavirus strain, severe acute respiratory syndrome (SARS-CoV-2) has spread to different countries at an alarming rate. Faster transmission rate and genetic modifications have provoked scientists to search for an immediate solution. With an increasing death rate, it becomes important to throw some light on the life cycle of the virus and its associated pathogenesis in the form of lung inflammation through cytokine storm (CS) production. This paper highlights the different stages of viral-mediated inflammatory responses in the host respiratory system. Previously, known antiinflammatory drugs and therapeutic strategies that might show potential in controlling the CS of Coronavirus disease-2019 (COVID-19) is also mentioned in this study. Our critical analysis provides insights into the inflammation cycle induced in the lungs by early virus replication, downregulation and shedding of angiotensin-converting enzyme 2 (ACE2), and in the CS production. Identification of suitable targets within the inflammatory pathways for devising the therapeutic strategies useful in controlling the prognosis of COVID-19 finds a special mention in this article. However, antibody-dependent enhancement is the key aspect to consider before testing any drug/compound for therapeutic purposes. Our in-depth analysis would provide similarities and differences between the inflammatory responses induced by SARS-CoV and SARS-CoV-2, providing an excellent avenue to further look at how earlier outbreaks of coronaviruses were controlled and where new steps are required?
\end{abstract}

Keywords SARS-CoV-2 · COVID-19 · Lung inflammation · Cytokine storm · Therapeutic strategies · And antibodydependent enhancement

\begin{tabular}{|c|c|c|c|}
\hline \multicolumn{2}{|c|}{ Abbreviations } & IP & Interferon gamma induced protein \\
\hline \multirow[t]{2}{*}{ SARS-CoV } & Severe acute respiratory syndrome & $\mathrm{S}$ & Spike protein \\
\hline & coronavirus & M & Membrane protein \\
\hline \multirow{3}{*}{$\begin{array}{l}\mathrm{CoV} \\
\text { MERS-CoV }\end{array}$} & Coronavirus & $\mathrm{N}$ & Nucleocapsid protein \\
\hline & Middle-east respiratory syndrome & $\mathrm{E}$ & Envelope protein \\
\hline & coronavirus & Nsp & Nonstructural protein \\
\hline \multirow{3}{*}{$\begin{array}{l}\text { ARDS } \\
\text { COVID-19 } \\
\text { IL }\end{array}$} & Acute respiratory distress syndrome & Rep & Replicase gene \\
\hline & Coronavirus disease 2019 & mRNA & Messenger RNA \\
\hline & Interleukin & ORF & Open reading frame \\
\hline TNF & Tumor necrosis factor & UTR & Untranslated region \\
\hline MCP & Monocyte chemoattractant protein & RBD & Receptor-binding domain \\
\hline $\mathrm{IFN} \gamma$ & Interferon & ACE2 & Angiotensin-converting enzyme 2 \\
\hline MIP & Macrophage inflammatory protein & ER & Endoplasmic reticulum \\
\hline \multirow[t]{2}{*}{ G-CSF } & Granulocyte colony-stimulating factor & TMPRSS2 & Transmembrane protease serine 2 \\
\hline & & DPP4 & Dipeptidyl peptidase 4 \\
\hline \multirow{2}{*}{\multicolumn{2}{|c|}{$\begin{array}{l}\text { Md. Imtaiyaz Hassan } \\
\text { mihassan@jmi.ac.in }\end{array}$}} & FDA & Food and Drug Administration \\
\hline & & NLRP3 & NOD-like protein receptor \\
\hline & & RAS & Renin-angiotensin system \\
\hline \multirow{2}{*}{\multicolumn{2}{|c|}{$\begin{array}{l}\text { Division of Biochemistry, Indian Agricultural Research } \\
\text { Institute, New Delhi 110012, India }\end{array}$}} & TH17 & T helper cells \\
\hline & & TH1 & $\mathrm{T}$ helper cell \\
\hline $\begin{array}{l}\text { Centre for } \\
\text { Jamia Mill }\end{array}$ & $\begin{array}{l}\text { terdisciplinary Research in Basic Sciences, } \\
\text { Islamia, Jamia Nagar, New Delhi 110025, India }\end{array}$ & JAK & Janus kinase \\
\hline
\end{tabular}




$\begin{array}{ll}\text { STAT } & \begin{array}{l}\text { Signal transducer and activator of transcrip- } \\ \text { tion protein }\end{array} \\ \text { ADCC } & \text { Antibody-mediated cell cytotoxicity } \\ \text { ADE } & \text { Antibody-dependent enhancement effect } \\ \text { FCR } & \text { Fc receptor } \\ \text { Nab } & \text { Neutralizing antibodies } \\ \text { TYK } & \text { Tyrosine protein kinase } \\ \text { CS } & \text { Cytokine storm } \\ \text { NCP } & \text { Novel coronary pneumonia } \\ \text { RA } & \text { Rheumatoid arthritis } \\ \text { TCZ } & \text { Tocilizumab } \\ \text { CXCR4 } & \text { C-X-C-chemokine receptor type 4 } \\ \text { PAMP } & \text { Pathogen-associated molecular patterns }\end{array}$

\section{Introduction}

Multiple cases of pneumonia in patients were reported in December 2019 from Wuhan hospitals in China [1]. All the cases had a common history of exposure to the seafood market of the Hubei Province of China [2]. The virus was later found to be the new and the seventh strain of the Coronaviruses (CoVs) family causing acute respiratory illnesses in humans [2]. Later, many confirmed cases did not show any travel history to the seafood market confirming the transmission of the virus that might have happened on a large scale [3].

CoVs belong to large families of enveloped viruses, having a positive-sense single-stranded RNA genome [4]. Bats are considered as the natural reservoirs of different CoVs [5]. The likely transmission to human species might have occurred through coming in direct contact of bats; however, multiple sources are claiming the presence of intermediate hosts responsible for the viral transmission [6]. In the case of Severe Acute Respiratory Syndrome (SARS-CoV-2), the genomic similarity of the receptor-binding domain (RBD) in the spike gene of the virus is greater to the pangolins (97.4\%) than bats (89.2\%) [5]. Also, 5 amino acids are similar in the RBD region of pangolins and SARS-CoV-2 whereas only one amino acid similarity exists between bats and the RBD domain of the virus, indicating pangolins as intermediate hosts through which human transmission has occurred [7, 8]. Although, the fatality rate of SARS-CoV-2 is much less than the previous outbreaks of $\mathrm{CoVs}$ the higher transmission rate generates a huge concern in controlling the rapid spreading of the disease $[9,10]$. The periodical reoccurrence of novel CoVs after every decade is attributed to their broad existence in nature, diversity in genomic structures supporting their more frequent recombination, and in an increase of the human to animal interfacing interactions [2].

SARS-CoV-2 enters into the host for completing its life cycle [11]. Macrophages identify the pathogen-associated molecular patterns (PAMP) and trigger innate immunity [12,
13]. The severity of the disease is associated with the production of a cytokine storm (CS) by the macrophages inside the host cell post-viral attack [14]. Increased secretion of cytokines such as IL-1 $\beta$, IP-10, MCP-1, IL-4, IL-10, and IFN- $\gamma$ was similar as observed in SARS-CoV [15]. Also, patients at high risk of mortality show higher production of cytokines including IL-2, IL-10, GCSF, IP-10, MCP-1, IL-7, TNF- $\alpha$, and MIP-1A [15].

Since, CS is an important concern in causing the virus associated lung inflammatory responses in the host, drugs targeting these pro-inflammatory cytokines may be an ideal strategy for overcoming the Coronavirus disease-2019 (COVID-19) pandemic [16, 17]. Several diagnostic and therapeutic approaches were undertaken to handle COVID-19 [18-22]. Here, we have reviewed different stages of inflammatory response mediated by the entry of SARS-CoV-2 in the human lung cells. Different therapeutic drugs that might show potential in targeting CS production are also described in detail. Figure 1 illustrates the plan of review, the areas that have been covered, and the highlights.

\section{The viral-mediated inflammatory response in the host}

The inflammatory response generated by SARS-CoV-2 results in the formation of acute lung injuries, pneumonia, and death [23]. These pathological conditions are the result of CS generated through early virus entry and replication [24]. There are different stages in which inflammatory and immune responses are generated once the virus enters into the host body through interaction with the Angiotensin-converting enzyme 2 (ACE2) receptors [25, 26]. (Fig. 2). An earlier study on SARS-CoV and its inflammatory pathways provide an important view of how the inflammation cycle might be happening in SARS-CoV-2 owning to their $80 \%$ genetic similarity.

\section{Inflammation by early virus replication}

The use of the same receptors ACE2 by SARS-CoV-2, as used by SARS-CoV, suggests the probability of targeting and infecting the same cells for initiating an infection [5, 27]. The replication of the virus is associated with apoptosis of epithelial and endothelial cells causing vascular leakage for the release of pro-inflammatory chemokines. Macrophages and lymphocytes may also undergo pyroptosis by this mechanism [28]. Pyroptosis occurs by the activation of viroporin 3 a upon early viral replication which further activates NOD-like receptor protein 3 (NLRP3) [29]. This receptor causes increased synthesis of IL-1 $\beta$ in macrophages inducing pyroptosis and the release of pro-inflammatory cytokines [30]. The presence of pulmonary infiltrates of lymphocytes 


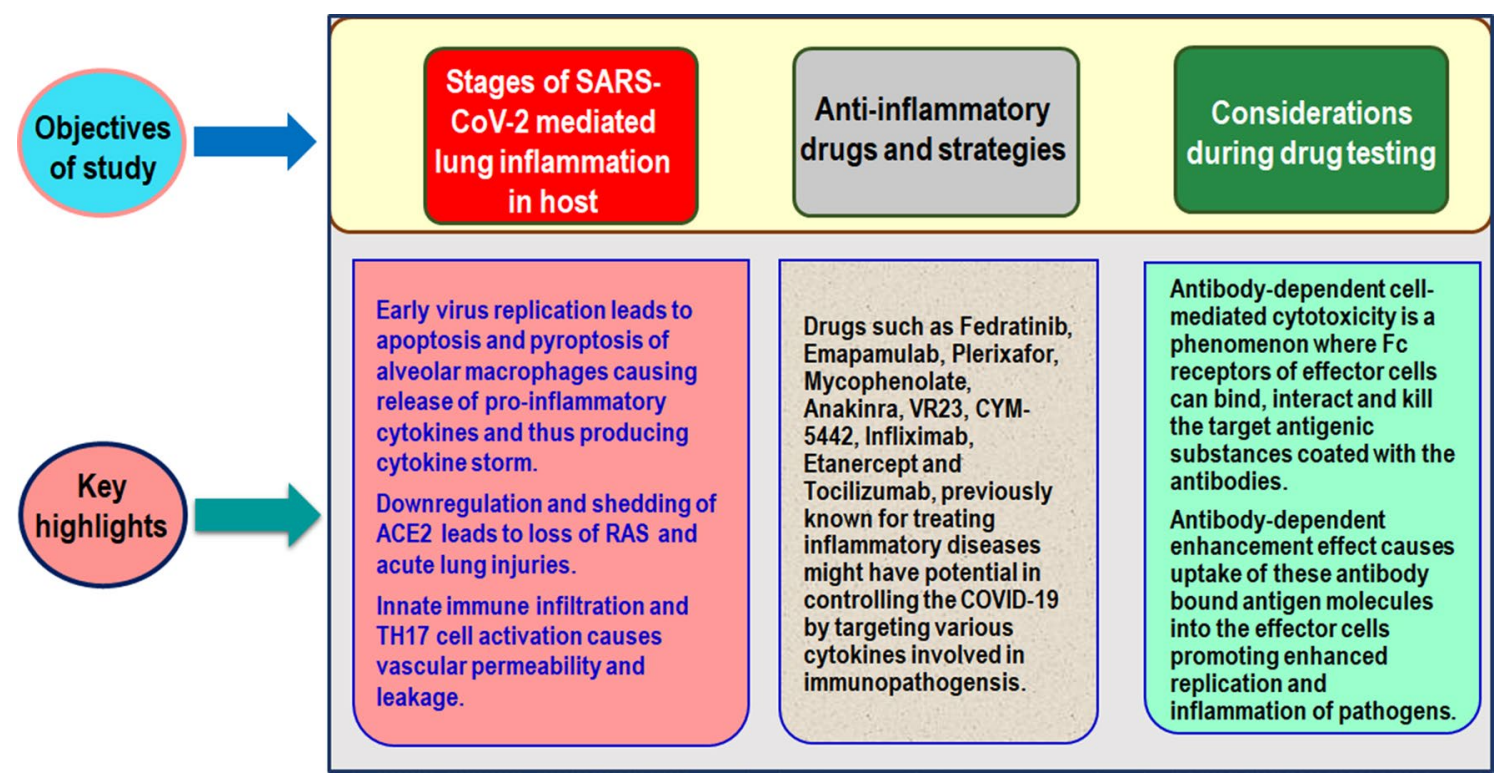

Fig. 1 Illustration of plans and highlights of the current study. Figure shows three major objectives of the study covered in this article and their associated key features summarizing the main findings

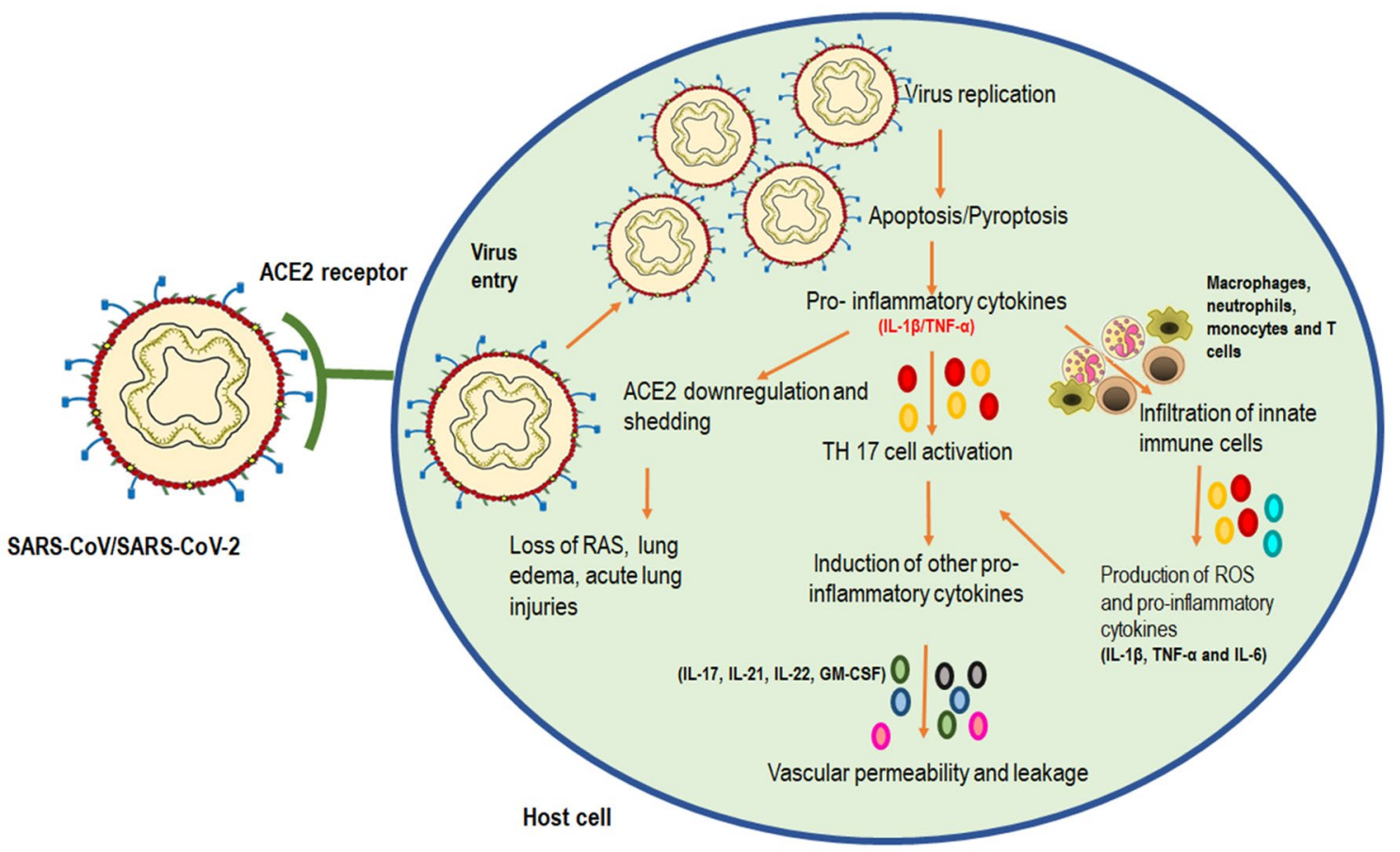

Fig. 2 Immunopathogenesis initiated by SARS-CoV-2 replication in promoting the respiratory infection. The binding of SARS-CoV/ SARS-CoV-2 on ACE2 of human lung cells causes increased viral uptake replication. This mediates apoptosis/pyroptosis of alveolar macrophages leading to the production of pro-inflammatory cytokines such as IL-1 $\beta$ and TNF- $\alpha$. These cytokines further perform three actions: mediates ACE2 downregulation and shedding leading to loss of RAS, increased TH17 cell activation causing further secretion of other pro-inflammatory cytokines and causing infiltration of innate immune cells. These immune cells can further cause production of pro-inflammatory cytokines (IL-1 $\beta$, TNF- $\alpha$ and IL-6) mediating TH17 cell function and leading to vascular permeability and leakage as the final steps of lung inflammation in the host cells post-viral attack. Abbreviations- Interleukin $1 \beta$ (IL-1 $\beta$ ), Tumor necrosis factor (TNF- $\alpha$ ), Interleukin 17 (IL-17), Interleukin 21 (IL-21), Interleukin 22 (IL-22), Granulocyte-Macrophage Colony-Stimulating Factor (GM-CSF), T helper cells (TH 17), Renin-angiotensin system (RAS) 
and cell bodies after apoptosis, has been found in $82.1 \%$ of the positive patients suggesting peripheral blood lymphopenia induced by SARS-CoV-2 [15, 31].

\section{Inflammation by downregulation of ACE2 receptors}

ACE2 receptors are present in the human lungs that lower the blood pressure by converting angiotensin II to angiotensin. SARS-CoV-2 uses this receptor for entry into the host cell and then downregulates its function [32, 33]. It also sheds the catalytic subunit of this receptor [34, 35]. The loss of the renin-angiotensin system (RAS) may enhance vascular permeability, accumulation of neutrophils, lung edema, inflammation, and acute lung injuries [36-38]. The enhancement in ACE2 shedding can be mediated by both SARS-CoV and SARS-CoV-2 infection and further release of inflammatory cytokines such as IL- $1 \beta$ and TNF- $\alpha$ by viral replication [39]. However, S protein-induced ACE2 shedding is mainly seen in SARS-CoV induced infection. Although these receptors are known to be used by other CoVs such as HNL-63-CoV, their pathogenies are restricted in causing common cold as no ACE2 shedding has been associated with their infection cycle [39]. Thus, this reflects the likelihood of ACE2 shedding in inducing acute lung injury and dysfunction of the respiratory system. This also suggests the pathogenicity behind SARS-CoV infection and now the novel strain, SARS-CoV-2 [26].

\section{Generation of cytokine storm}

Damages to muscular organs like lungs, heart, and kidneys have been reported in the presence of CS in the serum levels of the patients suffering from SARS-CoV-2 infection [15, 40]. Higher amounts of IL-1 $\beta$, G-CSF, GM-CSF, MCP1, IFN $\gamma$, IP10, MIP1A, MIP1B, TNF $\alpha$, IL-2, IL-7, IL-8, IL-9, IL-10, IL-17 is found in non-ICU patients; however, elevated levels of IP10, IL-2, IL-7, IL-10, G-CSF, MIP1A, MCP1, and TNF $\alpha$ have been reported in critical patients in ICU [15]. TH17 and TH1 cells are primarily involved in imparting cytotoxicity (Fig. 3).

The two cytokines, IL- $1 \beta$ and TNF $\alpha$ promote the activity of TH17 cells inducing vascular permeability and leakage. This enables the secretion of other cytokines such as IL-17, IL-21, IL-22, and GM-CSF (also associated with TH1 cells in humans). All of these cytokines have profound roles in the induction of other pro-inflammatory cytokines mediating the inflammatory responses in the host cells. For example, IL-17 induces the synthesis of G-CSF required in the recruitment of neutrophils; in the synthesis of IL-1 $\beta$, TNF $\alpha$, and IL-6 producing symptoms such as fever; in

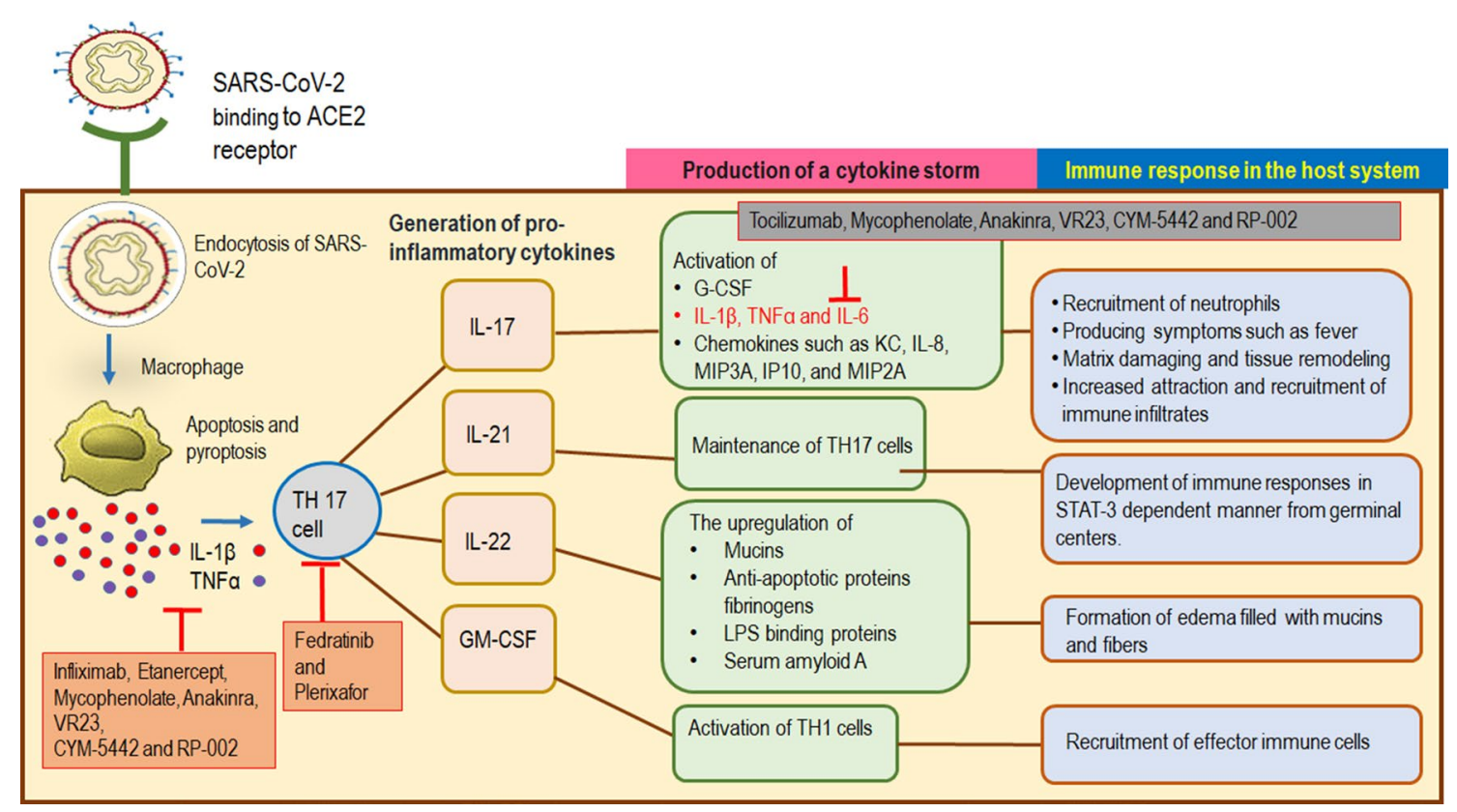

Fig. 3 A mechanism of TH 17 cell-mediated cytokine storm formation and immune responses in COVID-19 infected host. Binding of SARS-CoV-2 to ACE2 receptors of lung cells causes their endocytosis and further interaction with the alveolar macrophages triggering innate immunity. Apoptosis and pyroptosis of macrophages resulted in the production of IL-1 $\beta$ and TNF- $\alpha$ which activate TH17 cells for the production of pro-inflammatory cytokines, cytokine storm, and immune responses in the host system as described in the figure. The red arrow indicates the target area for the action of anti-inflammatory drugs (shown in orange boxes) that may be used in COVID-19 treatment. Abbreviations- Interleukin $1 \beta$ (IL-1 $\beta$ ), Tumor necrosis factor (TNF- $\alpha$ ), Interleukin 17 (IL-17), Interleukin 21 (IL-21), Interleukin 22 (IL-22), Granulocyte-Macrophage Colony-Stimulating Factor (GM-CSF), T helper cells (TH 17) 
matrix metalloproteinases that are actively engaged in damaging and remodeling of tissues; in chemokines KC, IL-8, MIP3A, IP10, and MIP2A that causes increased attraction and recruitment of immune infiltrates. IL-21 is required for the maintenance of TH17 cells and aids in the development of immune responses in the STAT-3 dependent manner from germinal centers. The upregulation of mucins, anti-apoptotic proteins, fibrinogens, LPS binding proteins, and serum amyloid A by IL-22 suggests its involvement in the formation of edema filled with mucins and fibers as observed in patients of SARS-CoV and SARS-CoV-2 [41, 42]. Higher numbers and expression of TH17 cells producing a CS was observed in critical patients of SARS-CoV-2 infection. However, the enhanced response of TH17 cells and IL-17 associated pathways are also detected in infections caused by SARS-CoV and MERS-CoV [43, 44]. Since TH17 cells have has been predominately involved in generating CS, causing pulmonary edema and damage to the lungs, scientists have suggested the use of inhibitors of TH17 cells as an appropriate way of controlling the infection [25].

The TH17 cell differentiation begins by elevated levels of IL-6 and IL-23 cytokines which activate JAK2. JAK2 further activates a receptor which in turn activates a transcription factor called STAT3 and mediates the differentiation and cellular response of TH17 cells (Fig. 4a) [45]. Studies support the use of JAK2 inhibitors in controlling the TH17 cell function (Fig. 4b). STAT3 inhibitors may also be effective in inhibiting the TH17 cell responses (Fig. 4c) but their active role in the B cell activation pathway through IL-21 signals (Fig. 4d) limits their use as a therapeutic strategy for CS production. In other terms, inhibition of STAT-3 may protect the patient from CS but it can also lead to B cell inactivation and therefore STAT inhibition is not preferred for COVID-19 patients. JAK2 does not disrupt these signals hence, targeting this would be an ideal strategy in drug preparation [25]. The drug for JAK2 inhibition has been discussed in the subsequent sections in detail.

\section{Anti-inflammatory drugs and strategies to COVID-19 treatment}

Different therapeutic strategies can be used in controlling the respiratory infection. These could involve either the use of JAK inhibitors that block TH17 cell activation and can further stop the generation of CS [25]. The drugs that block the $\mathrm{Fc}$ receptors on macrophages so that no antibody-dependent enhancement (ADE) could occur may also be used in cases where ADE associated lung inflammation predominates during the drug delivery [26]. Moreover, anti-inflammatory drugs that directly target the specific or non-specific cytokines produced by SARS-CoV-2 pathogenesis in the host system might also play a significant role in COVID-19 treatment [46] (Table 1).

Some of the anti-inflammatory drugs that have previously been used in different diseases such as in rheumatoid arthritis (RA), cancers, and immunosuppressants during transplant might hold potential in controlling SARS-CoV-2 infection as well [70]. Many ongoing trials are currently under study whose full potential in reducing the cytokine storm of COVID-19 patients should be tested.

\section{Fedratinib}

Fedratinib is a Food and Drug Administration (FDA) approved drug that is known to inhibit JAK2 (a mediator of TH17 cell differentiation for producing the CS). Researchers tested its efficacy in controlling myeloproliferative neoplasms on cytokine products of TH17 cells. It was found that Fedratinib decreased the CS produced by TH17 cells without inhibiting the activities of JAK1, JAK3, and TYK2 required for antiviral immunity. Fedratinib along with IL23 resulted in much better efficiency in controlling TH17 cell differentiation. Besides, JAK2 the drug also showed a significant reduction in expression of IL-22 by TH17 cells and GF-CSF, a cytokine-dependent upon JAK2 for transducing its signals [71]. Therefore, a JAK2 inhibitor, Fedratinib plays an important role in reducing the cytokine load generated in the critical patients suffering from SARS-CoV-2 infection and may be used as an effective treatment for combating COVID-19 at the moment [25].

\section{Tocilizumab}

Tocilizumab (TCZ) is a recombinant monoclonal antibody designed to block both membrane-bound and soluble IL-6 receptors and their associated signaling pathways [46]. This drug has been previously used for rheumatic diseases and in treating the severe cytokine release syndrome which is a life-threatening disorder caused by immunotherapy in cancer patients [72]. Various clinical trials have supported the efficacy of TCZ in the treatment of novel coronary pneumonia (NCP). It has also shown a considerable antagonistic effect on the host reaction stimulated by acute respiratory distress syndrome (ARDS) associated with COVID-19 [51]. In a study of 20 patients, $400 \mathrm{mg}$ of the dose was given intravenously. After a few days, fever and other symptoms of coronavirus were improved remarkably with better oxygenation capacity of the patient up to $75 \%$. The lesions observed through CT scan were also improved in $90.5 \%$ patients and $52.6 \%$ of patients showed normal levels of peripheral lymphocytes. This study had raised a potential area for more such randomized trials in the treatment of COVID-19 (to be published). Another study performed on 21 critical cases of COVID-19 says 


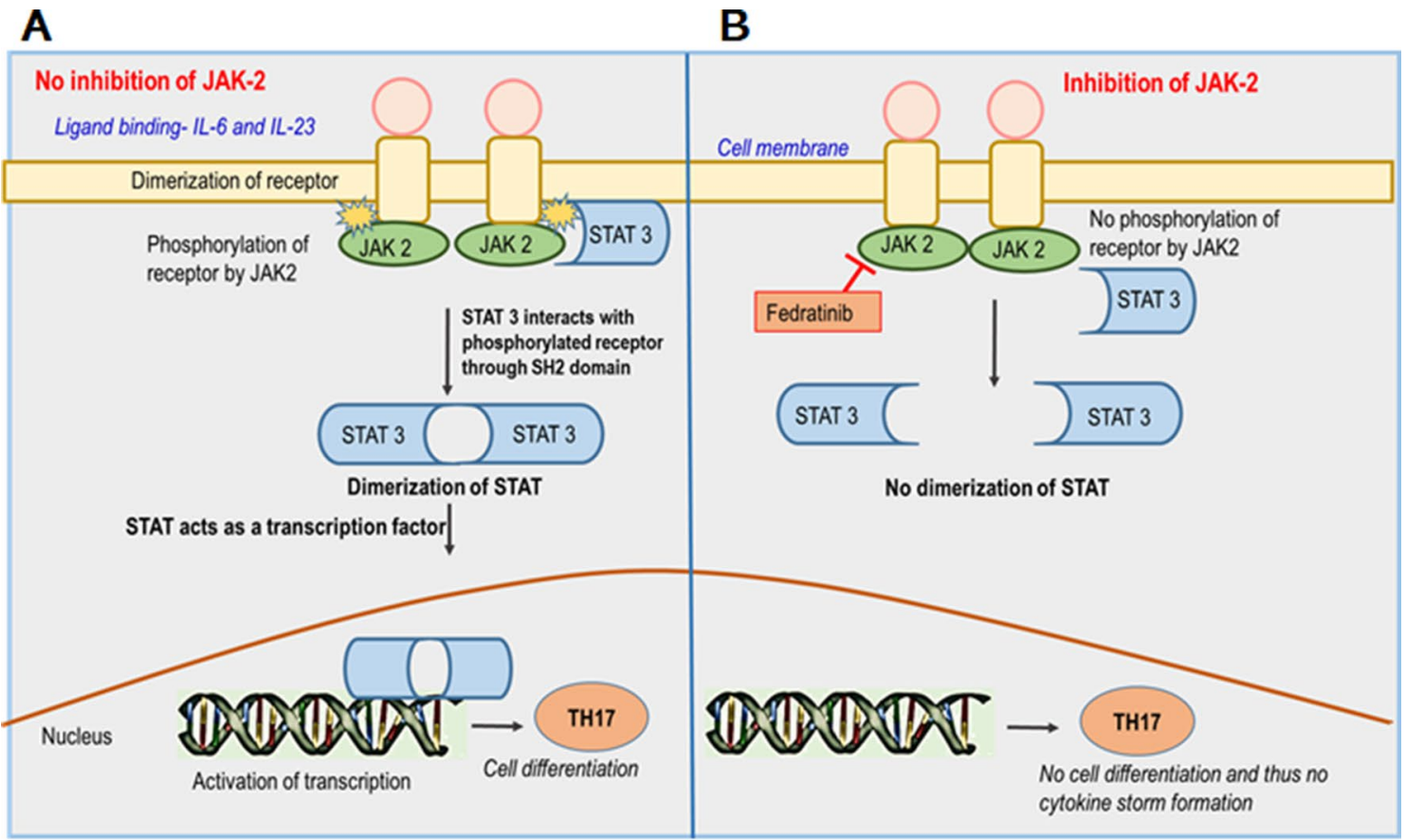

C

D

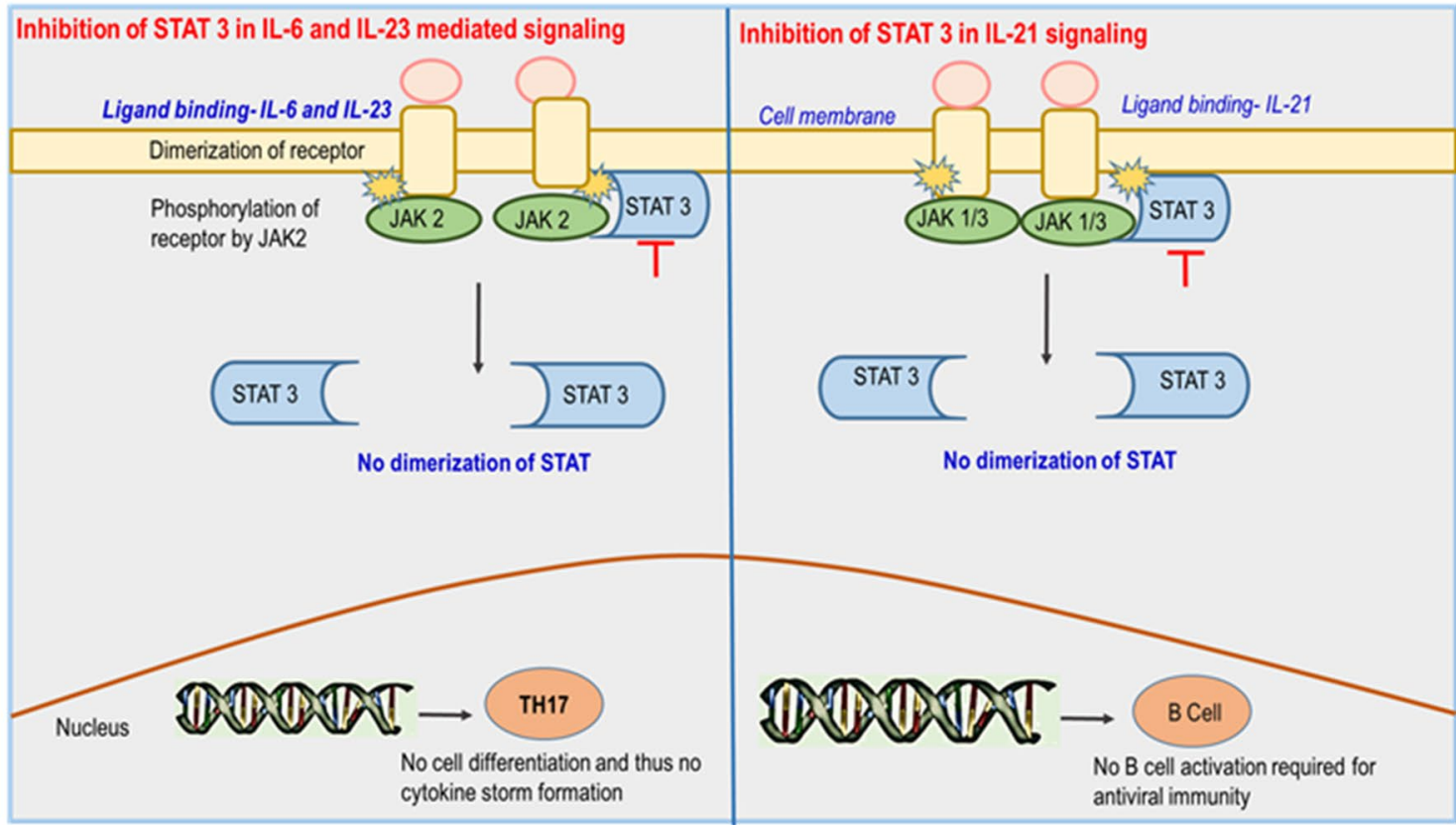

one or two doses of TCZ has promoted better recovery of the patients with reduced risk of death [47]. Since no toxicity has been observed with its usage, Chinese health authorities have included TCZ for managing pneumonia associated with COVID-19. The timing of administration of this drug needs to be monitored as in some cases earlier administration of this drug proved to be better in reducing the IL-6 signaling [48].

\section{Emapalumab}

Emapalumab is an IgG1 human monoclonal antibody that has a high affinity towards INF- $\gamma$ [49]. This is an FDA approved drug for the treatment of multiple organ failure caused by hyper inflammation [50]. Blocking of this free and membrane-bound receptor could prevent the hyperreaction of the host against SARS-CoV-2 [70]. 
4Fig. 4 Effect of JAK-2 and STAT-3 inhibitions in the regulation of TH17 cell differentiation and their consequences. a Shows the signaling of TH17 cells through the JAK-STAT pathway without the use of any inhibitors. Binding of IL- 6 and IL-23 cytokines cause the dimerization of the receptor. This allows JAK-2 a receptor-bound enzyme to phosphorylate the tyrosine residues of the receptor for its activation. STAT-3 now interacts with the phosphorylated receptor with its SH2 domain and its dimerization occurs. The dimer travels to the nucleus and starts acting as a transcription factor. TH17 cell differentiation occurs through this mechanism leading to the formation of cytokine storm in COVID-19 patients. b Describes the effect of the JAK2 inhibitor on TH17 cell signaling. No phosphorylation of the receptors would occur in the absence of an active JAK2 and hence no STAT activation for transcription. TH17 cell differentiation could not occur and the patient may be cured for COVID-19 without the production of the cytokine storm. c Shows the effect of STAT-3 inhibitors on signaling of TH17 cells mediated by IL- 6 and IL-23 ligands in the JAK-STAT pathway. Binding of IL- 6 and IL-23 cytokines cause the dimerization of the receptor. This allows JAK-2 a receptor-bound enzyme to phosphorylate the tyrosine residues of the receptor for its activation. STAT-3 now interacts with the phosphorylated receptor with its SH2 domain. The use of inhibitors for STAT-3 now prevents STAT dimerization for acting as a transcription factor, as a result, no TH17 cell differentiation occurs through this mechanism, and no formation of cytokine storm in COVID-19 patients. d Describes the effect of STAT-3 inhibitors on B cell activation required for the antiviral immunity by IL-21 ligand in the JAK-STAT pathway. Binding of IL-21 cytokine causes the dimerization of the receptor. This allows JAK-1/3 a receptor-bound enzyme to phosphorylate the tyrosine residues of the receptor for its activation. STAT-3 now interacts with the phosphorylated receptor with its $\mathrm{SH} 2$ domain. The use of inhibitors for STAT-3 now prevents STAT dimerization for acting as a transcription factor, as a result, no B cell activation occurs through this mechanism, and no formation of immunity against SARS-CoV-2 infection. The red arrow indicates the target area for the action of drugs known as Fedritanib. (Shown in the orange box). Abbreviation: IL Interleukin, JAK Janus kinase, STAT signal transducer and activator of transcription, $\mathrm{SH} 2 \mathrm{Src}$ homology domain

\section{Infliximab and Etanercept}

Defense mechanisms of the host after exposure to an antigen is often associated with the production of TNF- $\alpha$, a pro-inflammatory cytokine produced by brain cells such as astrocytes and microglia, macrophages, endothelial cells, lymphoid cells, adipose tissue, and cardiac myocytes [66]. They have profound roles in producing fever, in arresting the growth of cancer cells, and in inhibiting the viral replication upon their interaction with the host [65]. Infliximab is a monoclonal antibody that targets TNF- $\alpha$ [69] and Etanercept is a protein that fuses with the TNF- $\alpha$ receptor causing its inactivation [67]. The role of these drugs in RA and other immune disorders suggests their role in combating the main initiator TNF- $\alpha$ of CS in COVID-19 patients [68].

\section{Plerixafor}

Plerixafor is an antagonist of $\mathrm{CXCR}_{4}$, a receptor required for the chemotaxis of inflammatory cells such as monocytes, lymphocytes, and neutrophils [52]. Plerixafor causes attenuation of TH17 cells and reduces the inflammatory cells to enter into the airway further reducing the levels of IL-4, IL-5, and IL-13 in the lungs preventing acute lung injuries [73].

\section{Mycophenolate}

Mycophenolate contains mycophenolic acids which are being used as an immunosuppressive agent for the patients of kidney transplants [53]. There are two ways through which this drug actions-in the first case it causes a reduction in the levels of guanosine and deoxyguanosine nucleotide by inhibiting an enzyme called inositol monophosphate dehydrogenase finally causing impairment in the activities of $B$ and T lymphocytes [70]. The other action of mycophenolate lies within its ability to inhibit the mRNA expression of various pro-inflammatory cytokines such as IL-6, TNF- $\alpha$, and IL-1 $\beta[55,74]$. Earlier this has proved to possess a noncompetitive inhibiting ability of Middle-east Respiratory Syndrome (MERS-CoV)- papain-like protease [56]. The side effects of this drug have also been described involving diarrhea, urinary infections, and leukopenia [54].

\section{Anakinra}

Anakinra is an antagonist of the IL-1 receptor previously known for its efficacy against RA. Monocyte macrophage cells synthesize two stimulatory cytokines IL- $1 \beta$ and IL- $1 \alpha$ that act as initiators of the inflammatory signaling pathway therefore if any drug blocks their receptors it is hypothesized it will stop the production of CS $[57,75]$. Some of the studies centralized towards the use of anakinra showed a better flow of oxygen, prevention against mechanical ventilation, and provided information about the markers of blood inflammation without any signs of toxicity [58]. One of the limitations associated with its use was its ability to generate an infection at the site of injection of the drug [59].

\section{VR23}

Certain proteasome inhibitors harbor anti-inflammatory properties that may be an ideal strategy to target the CS. VR23 is a proteasomal inhibitor that reduces IL-6 levels in RA patients, secretion of TNF- $\alpha$, tissue inflammation and decreases the neutrophil migration improving the acute lung injury induced by LPS (lipopolysaccharide) in mouse models [60].

\section{CYM-5442 and RP-002}

Sphingosine-1-Phosphate (S1p) receptor is present in lymphocytes and endothelial cells in the lung tissues [61]. Agonists of this receptor, CYM-5442, and RP-002 have shown 


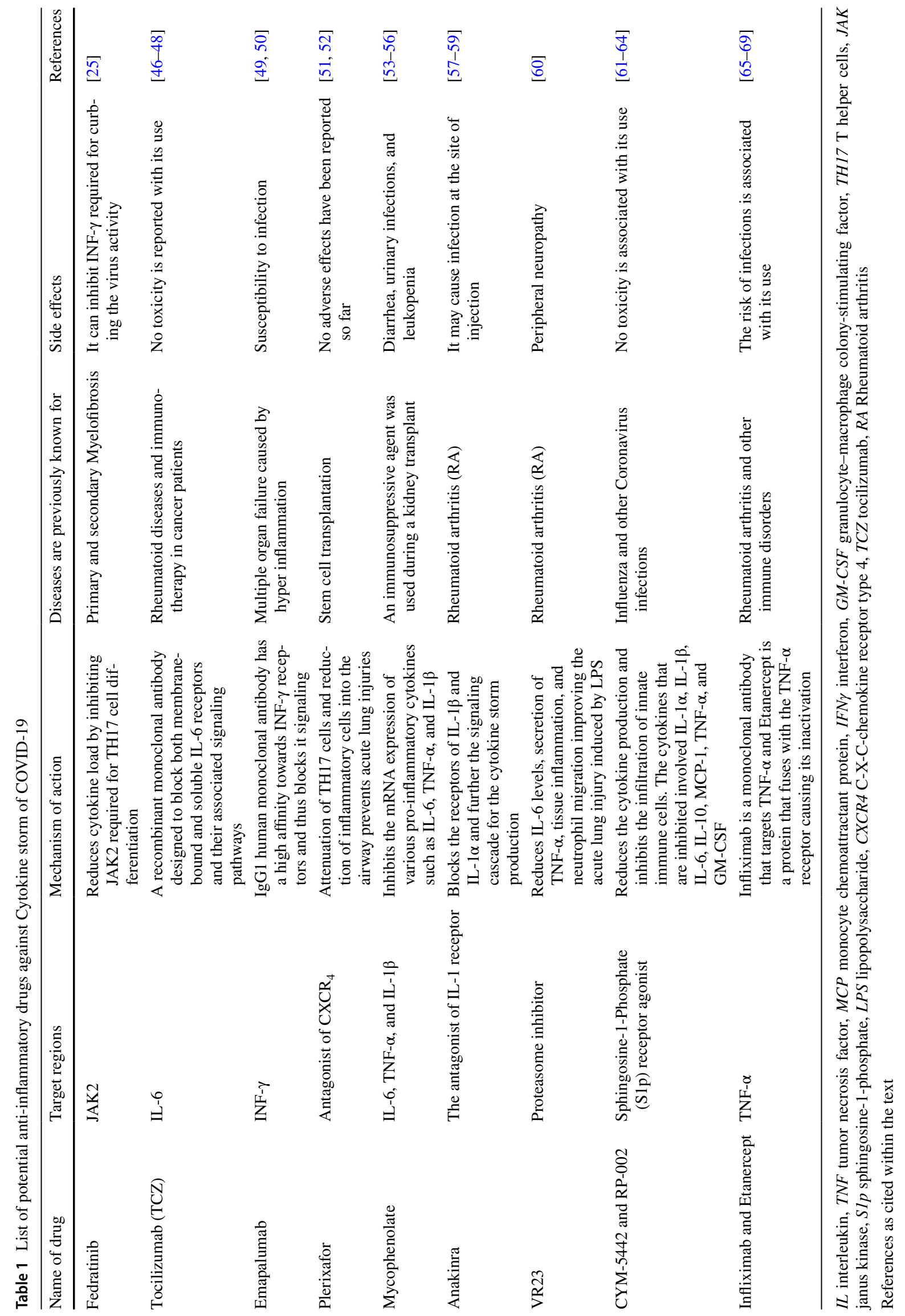


a considerable effect against severe influenza infection in the past. During the influenza infections of 2009, these agonists protected the mouse models from death by reducing cytokine production and by inhibiting the infiltration of innate immune cells [63]. The cytokines that were inhibited involved IL- $1 \alpha$, IL-1 $\beta$, IL-6, IL-10, MCP-1, TNF- $\alpha$, and GM-CSF. $80 \%$ protection to the mouse models was provided by these drugs; however, in combination with oseltamivir, mouse mortality reduced to $96 \%$ [64]. Interestingly, a patient of COVID-19 with pre-existing comorbidity of multiple sclerosis got successfully treated by this drug [62].

\section{Consideration during drug testing}

Antibody-dependent cell-mediated cytotoxicity (ADCC) or antibody-dependent cellular cytotoxicity is a phenomenon where Fc receptors of effector cells can bind, interact, and kill the target antigenic substances coated with the antibodies. However, in some cases, ADE causes uptake of these antibody-bound antigen molecules into the effector cells promoting their enhanced replication and inflammation. Therefore, ADE should be an important aspect to be considered before proceeding for clinical trials of any drugs for therapeutic and vaccine development.

\section{Inflammation by ADE effect}

Liu et al. [76] have identified that the antiviral neutralizing antibodies targeted towards the spike protein of the virus instead of clearing the virus load have resulted in altered inflammatory responses resulting in severe lung injury. The mechanism behind the anti-Spike IgG antibodies (anti-S$\mathrm{IgG}$ ) mechanism is partially understood but it is hypothesized that the antibodies bind to Fc receptors present on alveolar macrophages leading to the production of proinflammatory cytokines such as MCP-1 and IL- 8 in the lungs. They may also activate the classical complement pathway for mediating cell cytotoxicity [76]. But the major question that comes up is why only certain people face the adverse effects of ADCC while others can show a cleared viral load. This is perhaps because of the ADE that instead of reducing the viral infection promotes its replication and lung inflammation in a few patients. ADE allows anti-SIgG antibodies bound to $\mathrm{Fc}$ receptors of macrophage cells to enter, replicate, and to produce pro-inflammatory cytokines [77-79]. Thus, this effect may support both viral replication and the inflammatory responses in the patient's lungs. The other report says that they are two types of responses generated by the binding of anti-S-IgG antibodies to the Fc receptors. The primary response is less severe and the majority of people can combat it. This involves ACE2 shedding upon early viral replication leading to higher cytokine production and cellular injury through apoptosis/pyroptosis. Secondary response leads to the generation of an adaptive immune response where neutralizing antibodies (NAb) plays an essential part. About $80 \%$ of SARS-CoV infected patients had reported respiratory diseases after anti-IgG exposure [80]. FcR mediated cytotoxicity can thus be controlled by blocking these receptors [81, 82]. Different approaches to obstructing their interaction with IgG antibodies have been discussed in the next section.

\section{Strategies in preventing the ADE effect}

Three different approaches can be used in obstructing the interaction of the viral-NAb complex with Fc receptors on macrophages to prevent the ADE effect. Firstly, the use of antibodies or small molecule inhibitors that blocks the IgG-binding domain of $\mathrm{Fc}$ receptors can solve the purpose; Secondly, FC $\gamma$ RIIB may be used for inhibition of FCR activation. Various antibodies are available that have profound roles as immune suppressors [83, 84]. Thirdly, neonatal Fc receptor $(\mathrm{FcRn})$ can be also be targeted for inhibition of FCR activation. These receptors are required for extending the half-life of the $\operatorname{IgG}$ antibody. Preventing the interaction with IgG and FcRn may be achieved by the use of antibodies or small molecules that causes the required blockage and thus, there will be a decrease in the circulating levels of the $\operatorname{IgG}$ [85]. Also, saturation in the binding ability of FcRn to IgG can be achieved through the supply of intravenous immunoglobulin (IVIG) [86]. We have mainly focused on blocking FCR for controlling ADCC, however, there is a possibility that cell uses the classical complement pathway for cellular damage. Thus, antibodies and molecules inhibiting c5 and c5a factors of the classical complement pathway can also be devised for reducing the severity of the infection and reversing the effects of ADCC [87].

\section{Conclusion}

This article highlights the inflammatory response of the host initiated upon the subsequent interaction of SARSCoV-2 with human lung cells. The clinically approved anti-inflammatory drugs that might be useful in controlling the CS, provides new insights into what new strategies could be employed for further research in this field. Despite enormous efforts in producing the antiviral therapies, no specific clinical treatment exists so far and only partial information is known about the immunopathogenesis of SARS-CoV-2 infection suggesting the need to direct the future research in identifying the unexplored mechanisms. This study closes with a few research questions that need to be addressed for stepping closer towards achieving planetary health. Does our current knowledge 
of immunopathogenesis and inflammatory responses are sufficient enough in controlling the SARS-CoV-2 pandemic? Does inhibiting the JAK-STAT pathway could eliminate CS production? Are there any other alternative strategies that the host adopts to produce the CS if the JAK-STAT pathway is inhibited for TH17 cell differentiation? What is the true potential of anti-inflammatory drugs as a therapeutic intervention for targeting the pro-inflammatory cytokines and chemokines? Focusing research on these questions would shape our current understanding and knowledge on SARS-CoV-2 mediated inflammatory responses of the host and may provide suitable strategies in controlling the lung inflammation.

\section{Future directions}

The alarming rate of infection caused by COVID-19 in different countries of the world urges to look for immediate effective treatment and vaccine. Some poor and middleincome countries are facing problems in the diagnosis of infected patients. Higher IL- 6 and IL-10 cytokines are important in deciding the prognosis of COVID-19 and hence, can be used as a marker for the diagnosis of infection. The use of glucocorticoids during the SARS-CoV outbreak in 2003 had been a great immunomodulatory therapy in providing a better oxygenation environment to the patient and in relieving the symptoms such as fever and pneumonia associated with the CoV infections [88, 89]. However, their influence on the SARS-CoV-2 inflammatory response is not well-supported by clinical trials as of now [90]. Although their role is still unclear in clearing viral pneumonia and ARDS, certain studies claiming their ability to reduce CS manifestation suggests a probable area to be explored for future studies [15, 91, 92]. Some studies say that PARP inhibitors such as rucaparib can restore the activity of IFN-I in the Zika virus promoting the antiviral activity and this may be beneficial when comes to SARS-CoV-2 infection $[93,94]$. Also, Pioglitazone is a PPAR $\gamma$ agonist that reduces the inflammatory factors in the plasma generating an antiinflammatory effect against fibrosis and lung inflammation $[95,96]$. Since the tolerability of this drug is quite high, it has the potential to be explored for the amelioration of lung injuries in COVID-19. Many antiviral drugs are in a phase of rapid development but somehow the anti-inflammatory drugs and the immune response of the host as a result of SARS-CoV-2 infection have failed to be noticed. ARDS is majorly a result of CS and targeting this would be a reasonable strategy that should be focused in the coming time. More clinical studies focusing upon the doses of administration, any side effects must be warranted.
Author contributions PA-Manuscript writing, acquisition of data, conception, and design of the study; $\mathrm{MIH}$-Conception and design of the study, manuscript revision, final approval of version before submission.

Funding MIH thanks the Indian Council of Medical Research for funding the study (Grant No. BIC/12(01)/2015).

\section{Compliance with ethical standards}

Conflict of interest The authors declare no conflict of interest.

\section{References}

1. Zhu N, Zhang D, Wang W, Li X, Yang B, Song J, Zhao X, Huang B, Shi W, Lu R (2020) A novel coronavirus from patients with pneumonia in China, 2019. N Engl J Med 382:727-733

2. Cui J, Li F, Shi Z-L (2019) Origin and evolution of pathogenic coronaviruses. Nat Rev Microbiol 17:181-192

3. Stoecklin SB, Rolland P, Silue Y, Mailles A, Campese C, Simondon A, Mechain M, Meurice L, Nguyen M, Bassi C (2020) First cases of coronavirus disease 2019 (COVID-19) in France: surveillance, investigations and control measures, January 2020. Eurosurveillance 25:2000094

4. Weiss SR, Leibowitz JL (2011) Coronavirus pathogenesis. In: Advances in virus research. Elsevier, pp 85-164

5. Zhou P, Yang X-L, Wang X-G, Hu B, Zhang L, Zhang W, Si H-R, Zhu Y, Li B, Huang C-L (2020) A pneumonia outbreak associated with a new coronavirus of probable bat origin. Nature 579:270-273

6. Lee P-I, Hsueh P-R (2020) Emerging threats from zoonotic coronaviruses-from SARS and MERS to 2019-nCoV. J Microbiol Immunol Infect 53:365-367

7. Zheng J (2020) SARS-CoV-2: an emerging coronavirus that causes a global threat. Int J Biol Sci 16:1678

8. Lam TT-Y, Jia N, Zhang Y-W, Shum MH-H, Jiang J-F, Zhu H-C, Tong Y-G, Shi Y-X, Ni X-B, Liao Y-S (2020) Identifying SARS-CoV-2-related coronaviruses in Malayan pangolins. Nature 583:282-285

9. Vabret N, Britton GJ, Gruber C, Hegde S, Kim J, Kuksin M, Levantovsky R, Malle L, Moreira A, Park MD (2020) Immunology of COVID-19: current state of the science. Immunity 52:910-941

10. Asrani P, Hasan GM, Sohal SS, Hassan MI (2020) Molecular basis of pathogenesis of coronaviruses: a comparative genomics approach to planetary health to prevent zoonotic outbreaks in the 21 st century. OMICS: J Integr Biol. https://doi.org/10.1089/ omi.2020.0131

11. Shereen MA, Khan S, Kazmi A, Bashir N, Siddique R (2020) COVID-19 infection: origin, transmission, and characteristics of human coronaviruses. J Adv Res 24:91-98

12. Liu H, Zhou K, Liao L, Zhang T, Yang M, Sun C (2018) Lipoxin A4 receptor agonist BML-111 induces autophagy in alveolar macrophages and protects from acute lung injury by activating MAPK signaling. Respir Res 19:1-11

13. Aggarwal NR, King LS, D’Alessio FR (2014) Diverse macrophage populations mediate acute lung inflammation and resolution. Am J Physiol Lung Cell Mol Physiol 306:L709-L725

14. Leong H-N, Chan K-P, Le Oon L, Koay ES, Ng L-C, Lee M-A, Barkham T, Chen MI, Heng B-H, Ling A-E (2006) Clinical and laboratory findings of SARS in Singapore. Ann Acad Med Singap $35: 332$ 
15. Huang C, Wang Y, Li X, Ren L, Zhao J, Hu Y, Zhang L, Fan G, Xu J, Gu X (2020) Clinical features of patients infected with 2019 novel coronavirus in Wuhan, China. The Lancet 395:497-506

16. Poduri R, Joshi G, Jagadeesh G (2020) Drugs targeting various stages of the SARS-CoV-2 life cycle: exploring promising drugs for the treatment of Covid-19. Cell Signal 74:109721

17. Naqvi AAT, Fatima K, Mohammad T, Fatima U, Singh IK, Singh A, Atif SM, Hariprasad G, Hasan GM, Hassan MI (2020) Insights into SARS-CoV-2 genome, structure, evolution, pathogenesis and therapies: structural genomics approach. Biochim Biophys Acta Mol Basis Dis 1866:165878

18. Shamsi A, Mohammad T, Anwar S, AlAjmi MF, Hussain A, Rehman M, Islam A, Hassan M (2020) Glecaprevir and Maraviroc are high-affinity inhibitors of SARS-CoV-2 main protease: possible implication in COVID-19 therapy. Biosci Rep 40:1256. https://doi.org/10.1042/BSR20201256

19. Mohammad T, Shamsi A, Anwar S, Umair M, Hussain A, Rehman MT, AlAjmi MF, Islam A, Hassan MI (2020) Identification of high-affinity inhibitors of SARS-CoV-2 main protease: towards the development of effective COVID-19 therapy. Virus Res 288:198102

20. Fatima U, Rizvi SSA, Fatima S, Hassan MI (2020) Impact of hydroxychloroquine/chloroquine in COVID-19 therapy: two sides of the coin. J Interferon Cytokine Res. https://doi.org/10.1089/ jir.2020.0105

21. Kumari P, Singh A, Ngasainao MR, Shakeel I, Kumar S, Lal S, Singhal A, Sohal SS, Singh IK, Hassan MI (2020) Potential diagnostics and therapeutic approaches in COVID-19. Clin Chim Acta 510:488-497

22. Asrani P, Eapen MS, Chia C, Haug G, Weber HC, Hassan I, Sohal SS (2020) Diagnostic approaches in COVID-19: clinical updates. Expert Rev Respir Med. https://doi.org/10.1080/17476 348.2021 .1823833

23. Nikolich-Zugich J, Knox KS, Rios CT, Natt B, Bhattacharya D, Fain MJ (2020) SARS-CoV-2 and COVID-19 in older adults: what we may expect regarding pathogenesis, immune responses, and outcomes. Geroscience 42:505-514

24. Wang C, Xie J, Zhao L, Fei X, Zhang H, Tan Y, Zhou L, Liu Z, Ren Y, Yuan L (2020) Aveolar macrophage activation and cytokine storm in the pathogenesis of severe COVID-19

25. Wu D, Yang XO (2020) TH17 responses in cytokine storm of COVID-19: an emerging target of JAK2 inhibitor Fedratinib. J Microbiol Immunol Infect

26. Fu Y, Cheng Y, Wu Y (2020) Understanding SARS-CoV-2-mediated inflammatory responses: from mechanisms to potential therapeutic tools. Virol Sin 35:266-271

27. Zhao Y, Zhao Z, Wang Y, Zhou Y, Ma Y, Zuo W (2020) Single-cell RNA expression profiling of ACE2, the putative receptor of Wuhan 2019-nCov. BioRxiv. https://doi. org/10.1101/2020.01.26.919985

28. Yang M (2020) Cell pyroptosis, a potential pathogenic mechanism of 2019-nCoV infection. SSRN. https://doi.org/10.2139/ ssrn. 3527420

29. Chen N, Zhou M, Dong X, Qu J, Gong F, Han Y, Qiu Y, Wang J, Liu Y, Wei Y (2020) Epidemiological and clinical characteristics of 99 cases of 2019 novel coronavirus pneumonia in Wuhan, China: a descriptive study. The Lancet 395:507-513

30. Fink SL, Cookson BT (2005) Apoptosis, pyroptosis, and necrosis: mechanistic description of dead and dying eukaryotic cells. Infect Immun 73:1907-1916

31. Guan W-J, Ni Z-Y, Hu Y, Liang W-H, Ou C-Q, He J-X, Liu L, Shan H, Lei C-L, Hui DS (2020) Clinical characteristics of 2019 novel coronavirus infection in China. MedRxiv

32. Glowacka I, Bertram S, Herzog P, Pfefferle S, Steffen I, Muench MO, Simmons G, Hofmann H, Kuri T, Weber F (2010) Differential downregulation of ACE2 by the spike proteins of severe acute respiratory syndrome coronavirus and human coronavirus NL63. J Virol 84:1198-1205

33. Wang S, Guo F, Liu K, Wang H, Rao S, Yang P, Jiang C (2008) Endocytosis of the receptor-binding domain of SARS-CoV spike protein together with virus receptor ACE2. Virus Res 136:8-15

34. Lambert DW, Yarski M, Warner FJ, Thornhill P, Parkin ET, Smith AI, Hooper NM, Turner AJ (2005) Tumor necrosis factor- $\alpha$ convertase (ADAM17) mediates regulated ectodomain shedding of the severe-acute respiratory syndrome-coronavirus (SARS-CoV) receptor, angiotensin-converting enzyme-2 (ACE2). J Biol Chem 280:30113-30119

35. Jia HP, Look DC, Tan P, Shi L, Hickey M, Gakhar L, Chappell MC, Wohlford-Lenane C, McCray PB Jr (2009) Ectodomain shedding of angiotensin converting enzyme 2 in human airway epithelia. Am J Physiol Lung Cell Mol Physiol 297:L84-L96

36. Imai Y, Kuba K, Rao S, Huan Y, Guo F, Guan B, Yang P, Sarao R, Wada T, Leong-Poi H (2005) Angiotensin-converting enzyme 2 protects from severe acute lung failure. Nature 436:112-116

37. Kuba K, Imai Y, Penninger JM (2006) Angiotensin-converting enzyme 2 in lung diseases. Curr Opin Pharmacol 6:271-276

38. Imai Y, Kuba K, Penninger JM (2008) The discovery of angiotensin-converting enzyme 2 and its role in acute lung injury in mice. Exp Physiol 93:543-548

39. Haga S, Yamamoto N, Nakai-Murakami C, Osawa Y, Tokunaga K, Sata T, Yamamoto N, Sasazuki T, Ishizaka Y (2008) Modulation of TNF- $\alpha$-converting enzyme by the spike protein of SARS-CoV and ACE2 induces TNF- $\alpha$ production and facilitates viral entry. Proc Natl Acad Sci 105:7809-7814

40. Xu Z, Shi L, Wang Y, Zhang J, Huang L, Zhang C, Liu S, Zhao P, Liu H, Zhu L (2020) Pathological findings of COVID-19 associated with acute respiratory distress syndrome. Lancet Respir Med 8:420-422

41. Zenewicz LA (2018) IL-22: there is a gap in our knowledge. ImmunoHorizons 2:198-207

42. Tse GM, To K, Chan PK, Lo A, Ng K, Wu A, Lee N, Wong H, Mak S, Chan K (2004) Pulmonary pathological features in coronavirus associated severe acute respiratory syndrome (SARS). J Clin Pathol 57:260-265

43. Faure E, Poissy J, Goffard A, Fournier C, Kipnis E, Titecat M, Bortolotti P, Martinez L, Dubucquoi S, Dessein R (2014) Distinct immune response in two MERS-CoV-infected patients: can we go from bench to bedside? PLoS ONE 9:e88716

44. Josset L, Menachery VD, Gralinski LE, Agnihothram S, Sova P, Carter VS, Yount BL, Graham RL, Baric RS, Katze MG (2013) Cell host response to infection with novel human coronavirus EMC predicts potential antivirals and important differences with SARS coronavirus. MBio 4:e00165-13

45. Fabbi M, Carbotti G, Ferrini S (2017) Dual roles of IL-27 in cancer biology and immunotherapy. Mediat Inflamm 2017:1-14

46. Zhang W, Zhao Y, Zhang F, Wang Q, Li T, Liu Z, Wang J, Qin Y, Zhang X, Yan X (2020) The use of anti-inflammatory drugs in the treatment of people with severe coronavirus disease 2019 (COVID-19): The experience of clinical immunologists from China. Clin Immunol 214:108393

47. Xu X, Han M, Li T, Sun W, Wang D, Fu B, Zhou Y, Zheng X, Yang Y, Li X (2020) Effective treatment of severe COVID-19 patients with tocilizumab. Proc Natl Acad Sci 117:10970-10975

48. Michot J-M, Albiges L, Chaput N, Saada V, Pommeret F, Griscelli F, Balleyguier C, Besse B, Marabelle A, Netzer F (2020) Tocilizumab, an anti-IL-6 receptor antibody, to treat COVID19-related respiratory failure: a case report. Ann Oncol. https:// doi.org/10.1016/j.annonc.2020.03.300

49. Locatelli F, Jordan MB, Allen C, Cesaro S, Rizzari C, Rao A, Degar B, Garrington TP, Sevilla J, Putti M-C (2020) Emapalumab in children with primary hemophagocytic lymphohistiocytosis. $\mathrm{N}$ Engl J Med 382:1811-1822 
50. Al-Salama ZT (2019) Emapalumab: first global approval. Drugs 79:99-103

51. Chen C, Zhang X, Ju Z, He W (2020) Advances in the research of cytokine storm mechanism induced by Corona Virus Disease 2019 and the corresponding immunotherapies. Chin J Burns 36:E005-E005

52. Tian X, Xie G, Xiao H, Ding F, Bao W, Zhang M (2019) CXCR4 knockdown prevents inflammatory cytokine expression in macrophages by suppressing activation of MAPK and NF- $\mathrm{\kappa B}$ signaling pathways. Cell Biosci 9:55

53. Goldblum R (1993) Therapy of rheumatoid arthritis with mycophenolate mofetil. Clin Exp Rheumatol 11:S117

54. Hassan AV, Sinha MD, Waller S (2013) A single-centre retrospective study of the safety and efficacy of mycophenolate mofetil in children and adolescents with nephrotic syndrome. Clin Kidney J 6:384-389

55. Balestri R, Rech G, Girardelli C (2020) Occurrence of SARSCoV-2 during mycophenolate mofetil treatment for pemphigus. J Eur Acad Dermatol Venereol. https://doi.org/10.1111/jdv.16578

56. To KK, Mok K-Y, Chan AS, Cheung NN, Wang P, Lui Y-M, Chan JF, Chen H, Chan K-H, Kao RY (2016) Mycophenolic acid, an immunomodulator, has potent and broad-spectrum in vitro antiviral activity against pandemic, seasonal and avian influenza viruses affecting humans. J Gen Virol 97:1807-1817

57. So A, De Smedt T, Revaz S, Tschopp J (2007) A pilot study of IL-1 inhibition by anakinra in acute gout. Arthr Res Ther 9:R28

58. Aouba A, Baldolli A, Geffray L, Verdon R, Bergot E, MartinSilva N, Justet A (2020) Targeting the inflammatory cascade with anakinra in moderate to severe COVID-19 pneumonia: case series. Ann Rheum Dis. https://doi.org/10.1136/annrheumdis-2020217706

59. Ramírez J, Cañete JD (2018) Anakinra for the treatment of rheumatoid arthritis: a safety evaluation. Expert Opin Drug Saf 17:727-732

60. Durkin A, Vu H-Y, Lee H (2020) The VR23 antitumor compound also shows strong anti-inflammatory effects in a human rheumatoid arthritis cell model and acute lung inflammation in mice. J Immunol 204:788-795

61. Sanna MG, Liao J, Jo E, Alfonso C, Ahn M-Y, Peterson MS, Webb B, Lefebvre S, Chun J, Gray N (2004) Sphingosine 1-phosphate $(\mathrm{S} 1 \mathrm{P})$ receptor subtypes S1P1 and S1P3, respectively, regulate lymphocyte recirculation and heart rate. J Biol Chem 279:13839-13848

62. Barzegar M, Mirmosayyeb O, Nehzat N, Sarrafi R, Khorvash F, Maghzi A-H, Shaygannejad V (2020) COVID-19 infection in a patient with multiple sclerosis treated with fingolimod. Neurol Neuroimmunol Neuroinflamm 7:e753

63. Oldstone MB, Rosen H (2014) Cytokine storm plays a direct role in the morbidity and mortality from influenza virus infection and is chemically treatable with a single sphingosine-1-phosphate agonist molecule. In: Sphingosine-1-phosphate signaling in immunology and infectious diseases. Springer, pp 129-147

64. Oldstone MB, Teijaro JR, Walsh KB, Rosen H (2013) Dissecting influenza virus pathogenesis uncovers a novel chemical approach to combat the infection. Virology 435:92-101

65. Braumüller $\mathrm{H}$, Wieder T, Brenner E, Aßmann S, Hahn M, Alkhaled M, Schilbach K, Essmann F, Kneilling M, Griessinger C (2013) T-helper-1-cell cytokines drive cancer into senescence. Nature 494:361-365

66. Gaur U, Aggarwal BB (2003) Regulation of proliferation, survival and apoptosis by members of the TNF superfamily. Biochem Pharmacol 66:1403-1408

67. Jarvis B, Faulds D (1999) Etanercept. Drugs 57:945-966

68. Kristensen LE, Saxne T, Nilsson J-Å, Geborek P (2006) Impact of concomitant DMARD therapy on adherence to treatment with etanercept and infliximab in rheumatoid arthritis. Results from a six-year observational study in southern Sweden. Arthr Res Ther 8:R174

69. Markham A, Lamb HM (2000) Infliximab. Drugs 59:1341-1359

70. Scala S, Pacelli R (2020) Fighting the host reaction to SARSCOv-2 in critically Ill patients: the possible contribution of offlabel drugs. Front Immunol 11:1201

71. Bright JJ, Du C, Sriram S (1999) Tyrphostin B42 inhibits IL12-induced tyrosine phosphorylation and activation of Janus kinase-2 and prevents experimental allergic encephalomyelitis. J Immunol 162:6255-6262

72. Amlani A, Barber C, Fifi-Mah A, Monzon J (2020) Successful treatment of cytokine release syndrome with IL-6 blockade in a patient transitioning from immune-checkpoint to MEK/BRAF inhibition: a case report and review of literature. Oncologist. https://doi.org/10.1634/theoncologist.2020-0194

73. Chen H, Xu X, Teng J, Cheng S, Bunjhoo H, Cao Y, Liu J, Xie J, Wang C, Xu Y (2016) CXCR4 inhibitor attenuates ovalbumin-induced airway inflammation and hyperresponsiveness by inhibiting Th17 and Tc17 cell immune response. Exp Ther Med 11:1865-1870

74. Conti P, Ronconi G, Caraffa A, Gallenga C, Ross R, Frydas I, Kritas S (2020) Induction of pro-inflammatory cytokines (IL-1 and IL-6) and lung inflammation by Coronavirus-19 (COVI-19 or SARS-CoV-2): anti-inflammatory strategies. J Biol Regul Homeost Agents 34:1

75. Zeng QL, Yu ZJ, Gou JJ, Li GM, Ma SH, Zhang GF, Xu JH, Lin WB, Cui GL, Zhang MM, Li C, Wang ZS, Zhang ZH, Liu ZS (2020) Effect of convalescent plasma therapy on viral shedding and survival in COVID-19 patients. J Infect Dis 222:38-42

76. Liu L, Wei Q, Lin Q, Fang J, Wang H, Kwok H, Tang H, Nishiura K, Peng J, Tan Z (2019) Anti-spike IgG causes severe acute lung injury by skewing macrophage responses during acute SARS-CoV infection. JCI insight 4:e123158

77. Haslwanter D, Blaas D, Heinz FX, Stiasny K (2017) A novel mechanism of antibody-mediated enhancement of flavivirus infection. PLoS Pathog 13:e1006643

78. Ochiai H, Kurokawa M, Matsui S, Yamamoto T, Kuroki Y, Kishimoto C, Shiraki K (1992) Infection enhancement of influenza A NWS virus in primary murine macrophages by antihemagglutinin monoclonal antibody. J Med Virol 36:217-221

79. Takada A, Kawaoka Y (2003) Antibody-dependent enhancement of viral infection: molecular mechanisms and in vivo implications. Rev Med Virol 13:387-398

80. Peiris JSM, Chu C-M, Cheng VC-C, Chan K, Hung I, Poon LL, Law K-I, Tang B, Hon T, Chan C (2003) Clinical progression and viral load in a community outbreak of coronavirusassociated SARS pneumonia: a prospective study. The Lancet 361:1767-1772

81. Nimmerjahn F, Ravetch JV (2008a) Fc $\gamma$ receptors as regulators of immune responses. Nat Rev Immunol 8:34-47

82. Nimmerjahn F, Ravetch JV (2008) Analyzing antibody-Fcreceptor interactions. In: Innate immunity. Springer, Berlin, pp $151-162$

83. van Mirre E, van Royen A, Hack CE, Crow AR, Song S, Freedman J, Helgason CD, Humphries RK, Siminovitch KA, Lazarus AH (2004) IVIg-mediated amelioration of murine ITP via Fc $\gamma$ RIIb is not necessarily independent of SHIP-1 and SHP-1 activity. Blood 103:1973-1974

84. Veri MC, Gorlatov S, Li H, Burke S, Johnson S, Stavenhagen J, Stein KE, Bonvini E, Koenig S (2007) Monoclonal antibodies capable of discriminating the human inhibitory $\mathrm{Fc} \gamma$-receptor IIB (CD32B) from the activating Fc $\gamma$-receptor IIA (CD32A): biochemical, biological and functional characterization. Immunology 121:392-404

85. Nimmerjahn F, Ravetch JV (2008b) Anti-inflammatory actions of intravenous immunoglobulin. Annu Rev Immunol 26:513-533 
86. Kurlander RJ, Hall J (1986) Comparison of intravenous gamma globulin and a monoclonal anti-Fc receptor antibody as inhibitors of immune clearance in vivo in mice. J Clin Investig 77:2010-2018

87. Horiuchi T, Tsukamoto H (2016) Complement-targeted therapy: development of C5-and C5a-targeted inhibition. Inflamm Regen 36:11

88. Chen R-C, Tang X-P, Tan S-Y, Liang B-1, Wan Z-Y, Fang J-Q, Zhong N (2006) Treatment of severe acute respiratory syndrome with glucosteroids: the Guangzhou experience. Chest 129:1441-1452

89. Yam LY-C, Lau AC-W, Lai FY-L, Shung E, Chan J, Wong V, Group HKHASC (2007) Corticosteroid treatment of severe acute respiratory syndrome in Hong Kong. J Infect 54:28-39

90. Auyeung TW, Lee JS, Lai WK, Choi CH, Lee HK, Lee JS, Li PC, Lok KH, Ng YY, Wong WM (2005) The use of corticosteroid as treatment in SARS was associated with adverse outcomes: a retrospective cohort study. J Infect 51:98-102

91. Sun P, Lu X, Xu C, Sun W, Pan B (2020) Understanding of COVID-19 based on current evidence. J Med Virol 92:548-551

92. Chan KW, Wong VT, Tang SCW (2020) COVID-19: an update on the epidemiological, clinical, preventive and therapeutic evidence and guidelines of integrative Chinese-Western medicine for the management of 2019 novel coronavirus disease. Am J Chin Med 48:737-762

93. Mantlo E, Bukreyeva N, Maruyama J, Paessler S, Huang C (2020) Antiviral activities of type I interferons to SARS-CoV-2 infection. Antivir Res 179:104811

94. Li L, Zhao H, Liu P, Li C, Quanquin N, Ji X, Sun N, Du P, Qin C-F, Lu N (2018) PARP12 suppresses Zika virus infection through PARP-dependent degradation of NS1 and NS3 viral proteins. Sci Signal 11:1. https://doi.org/10.1126/scisignal.aas9332

95. Aoki Y, Maeno T, Aoyagi K, Ueno M, Aoki F, Aoki N, Nakagawa J, Sando Y, Shimizu Y, Suga T (2009) Pioglitazone, a peroxisome proliferator-activated receptor gamma ligand, suppresses bleomycin-induced acute lung injury and fibrosis. Respiration 77:311-319

96. Carboni E, Carta AR, Carboni E (2020) Can pioglitazone be potentially useful therapeutically in treating patients with covid19? Med Hypotheses 140:109776

Publisher's Note Springer Nature remains neutral with regard to jurisdictional claims in published maps and institutional affiliations. 